\title{
Expanding the functionality of automated monitoring systems for traction substations
}

\author{
Svetlana Makasheva ${ }^{1,{ }^{*}}$ and Pavel Pinchukov ${ }^{1}$ \\ ${ }^{1}$ Far Eastern State Transport University, Seryshev st. 47, 680021, Khabarovsk, Russia
}

\begin{abstract}
The paper deals with the problem of automated monitoring system improvement. The goal of the study is to create a controlling module of automated monitoring system for automation of calculations and assessment process of traction transformer's remaining life analysis. To achieve the goal, the modern power transformer's diagnostic systems and methods of scientific analysis are considered, full-scaled experimental study are used. To adjust the timing of the current and major repairs, it is proposed to improve this monitoring system by creating an additional module to determine the traction transformer's remaining life throughout its life cycle in real time and the formation of a warning system. Requirements to transformer's remaining life assess module are formulated. Calculation algorithm and program module for identifying the transformer's remaining life parameters are described. Benefits of introduction into the existing AMS a new additional module for calculating the transformer's remaining life are shown.
\end{abstract}

\section{Introduction}

The railway industry, like many other organizations, aims to finding an effective method for an automated, accurate and reliable system for monitoring and tracking different items and their parameters. Manually monitoring all the comprehenive equipment of railways and ensuring the continuous operation is obviously very difficult. In this case, the use of automated control and management systems would certainly help consolidate and improve the time of response to various kinds of failures and emergencies, thereby directly increasing the uptime.

The automated monitoring system (AMS) has widely feathers and can integrate measuring, protection, control, remote terminal unit (RTU), etc. Modern AMS accommodates intelligent electronic devices (IED) and fully integrates new technologies and equipment for condition monitoring, disturbance recording, control and protection.

The railways power supply system is a complex of engineering structures with a large number of elements. Traction substations are a combination of complex highly sophisticated electrical equipment. Thus, it was necessary that the AMS for traction substation would allow remotely monitoring, managing and retrieving information on emergencies at the substation.

\footnotetext{
*Corresponding author: jap svet@mail.ru
} 
In some cases, the system would automatically carry out control actions aimed at restoring efficient management.

Due to the above mentioned requires, AMS for monitoring objects of traction substation has been created and successfully operate in many countries of the world: China, India, Russia, Germany, etc. [1-4]. For example, the comprehensive system developed and produced by SAC Co., was put into operation in China in 2001 and up to now has been stable in operation [3].

According to information from the major large firms-developers of AMS, mainly the modern systems have [3-5]:

- module structure design;

- distributive data processing;

- large-capacity and high-speed real-time database and historical database;

- strong and high-efficiency data processing capacity;

- integration capacity to manufacturer products with different subsystems (protocol, data and working mode etc.);

- universal hardware and standard software, user-friendly interface.

In this way, informational support of AMS, in addition to allowing generality and simplicity of the information supplied, permits obtaining the reliable, timely, and relevant information. The integrated software is of the design principles of layering, distribution, high reliability, high safety and high real time, which guarantees the high-efficiency and stable operation of AMS.

Parameters measured by AMS at traction substation (current, voltage, phase angles, etc.) make it possible to use this information to solve a large variety of tasks - from equipment diagnostics to control its operation. This is interpreted as functionality expanding and often requires the creation of new (or adjustment of existing) software products for operated monitoring systems. In this regard, the aim of this paper is researching ASM's unrealized functions and software product creating, that allows the new functions implementation with its integration into the existing software environment.

\section{Materials and methods}

In this study the experimental research methods, based on full-scaled measurement of controlled parameters and subsequent calculation and analysis are used. The measurements were carried out for traction transformers of traction substations located at Far Eastern Region of Russia during last 12 years from 2006 to 2018 year [6-11].

Controlling module of automated monitoring system for calculation's automation and assessment process of traction transformer's remaining life analysis are created.

\section{Power transformer's remaining life analysis by means of AMS}

The power transformer, located on traction substation, is the one of most important and costly elements in the traction power supply system. High values of currents flowing through the windings of the transformer during heavy haul traffic lead to overheating of the windings. Overheating leads to an aging speed increasing of transformer's paper insulation and, as a consequence, to a decreasing transformer's reliability. The unexpected failure of a power transformer leads to a large economic loss and a sharp decrease in the safety of train traffic. The danger of a transformer failure can occur either suddenly (immediately) or as a result of a general deterioration in the transformer's condition during a long period. 
In order to extend the transformer's service life and timely service the need for different diagnostic methods and technology occurs. The main diagnostic methods on the subject of the study are chromatographic methods for diagnosing an oil-filled of equipment [12].

The method of diagnosing the state of equipment by composition and concentration of gases dissolved in oil: hydrogen $(\mathrm{H} 2)$, methane $(\mathrm{CH} 4)$, acetylene $(\mathrm{C} 2 \mathrm{H} 2)$, ethylene $(\mathrm{C} 2 \mathrm{H} 4)$, ethane $(\mathrm{C} 2 \mathrm{H} 6)$, carbon monoxide $(\mathrm{CO})$, carbon dioxide $(\mathrm{CO} 2)$ is used all over the world. With the help of Dissolved Gas Analysis (DGA), two groups of main defects can be detected: overheating of current-carrying joints and structural elements and electric discharges in oil. Presence of excess concentrations of dissolved in oil individual gases indicates the paper insulation's deterioration state, and the heating of solid and paper-oil insulation. Often this information is laid in the basis of existing power transformer's diagnostic systems and systems for transformer's remaining life's evaluation [12-14].

\subsection{Power transformer's diagnostic systems}

The transformer's operating reliability should be ensured under all circumstances. Its operating status therefore needs establishing and logging. All parameters for ensuring its function over its entire life must also be regulated. The main diagnostic systems for power transformers in the world are:

1) General Electric. Monitoring, control and diagnostics systems for high-voltage transformer equipment are represented by "GE Energy" as three brand names: HYDRAN®, FARADAY ${ }^{\circ \mathrm{TM}^{\circ}}{ }^{\mathrm{t} M E D I C}$ and Intellix ${ }^{\circledR}$. The "GE Energy" system has the equipment which can solve most of the prevailing types of transformer failure: an integrated sensor system, models for performing analysis, and data processing facilities. It is distinguished by a large number of monitored parameters and a large number of diagnostic models. For example, an insulation's wear model is used that calculates the wear rate in accordance with the IEEE or IEC guidelines, the cooling efficiency model, monitoring the real efficiency of the cooling system and others [13].

2) ABB: The ABB TES system for new transformers of this brand is built in at manufacture of the transformer; ABB T-monitor - for those in service transformers produced not only by $\mathrm{ABB}$, but also by other companies. Data collection ABB T-monitor: gases, moisture, temperature, load, etc. The data from the measuring instruments must be correctly interpreted. In traditional monitoring systems, threshold values are used to determine relay protection settings. When the protection is activated, the transformer is switched off and examined. But the setting of threshold values ABB T-monitor is ambiguous, because, on the one hand, at a trigger level close to critical, it is impossible to determine the tendency to failure in advance. On the other hand, if the protection is triggered too often (which occurs in traction substations during overloads associated with a heavy haul traffic), its efficiency will be questioned [14].

3) Reinhausen ("TAPCON-trol System"), Siemens («Siemens Legacy Transformer Monitoring \& Diagnostic System»), AREVA, Serveron (Serveron ${ }^{\circledR}$ Transformer Monitors): Systems allow visualizing the measured parameters and operating modes visually in different graphs, recording the current operational parameters of the on-load tap-changer, such as load current, temperature, motor drive data, torque of the on-load tap-changer and the position of the contacts when switching, at each switchover. Based on this data, system evaluates online the correctness of the execution of each current switching. If the limit value of the monitored parameter is exceeded, the special device locks the motor drive, thereby preventing damage to the on-load tap-changer and the transformer [15].

\subsection{Requirements to transformer's remaining life assess module}


All of the above diagnostic systems are designed for monitoring power transformers of the power supply system and are designed for normal operation mode. In the traction power supply system under conditions of sharply variable load and increasing rates of heavy haul traffic, the transformers operate for a long time under conditions of overloads. In addition, modern AMS installed on Russia's traction substations make it possible to adapt their parameters and program additional modules to assess the transformer's remaining life. Moreover, it does not require the purchase of external, additional diagnostic systems, which significantly saves money for modernization.

Therefore, it is proposed to directly measure and monitor the traction transformer's parameters on-line and the creation of an additional module for AMS. The module should automated calculate the temperature of the most heated point and the associated degree of paper insulation's wear in on-line mode and form an alarm system.

\section{Power transformer's remaining life assess module elaboration}

Automated calculation is proposed to be performed in on-line mode using AMS database using the Top-Oil Temperature method for calculating the temperature of the oil most heated point and insulation's thermal wear $[12,13,16]$. The proposed method assumes the using an ambient temperatures by direct its measurement in real time.

\subsection{Calculation algorithm elaboration}

The procedure of calculating the oil most heated point, insulation's thermal wear and estimating the transformer's remaining life in a simplified form is shown at Figure 1.

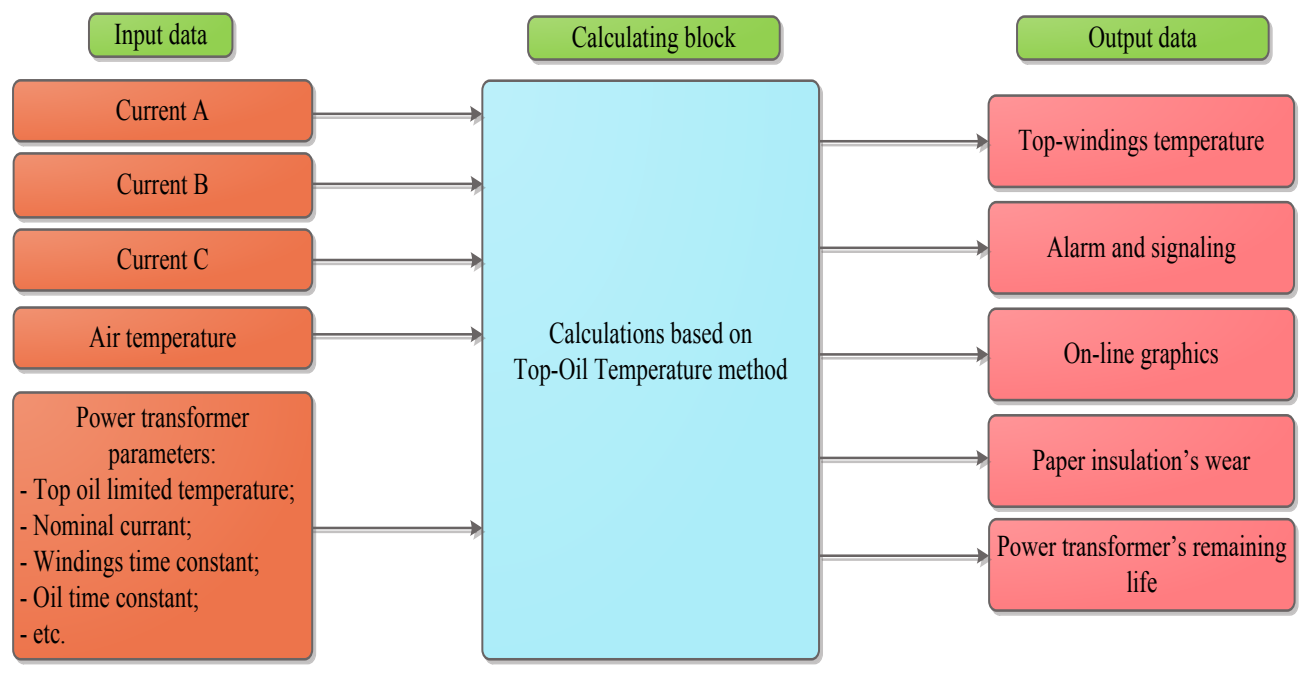

Fig. 1. Procedure of calculating

As follows from Figure 1, the main output characteristic of the calculating block is the predicted transformer's remaining life and it is perceived by the system as a predicted indicator. When the predicted indicator approaches 1 or less, a warning section appears in the output characteristics unit as alarms about the approaching expiration of the transformer's remaining life.

The calculation algorithm of power transformer's remaining life assess is shown at Figure 2. 


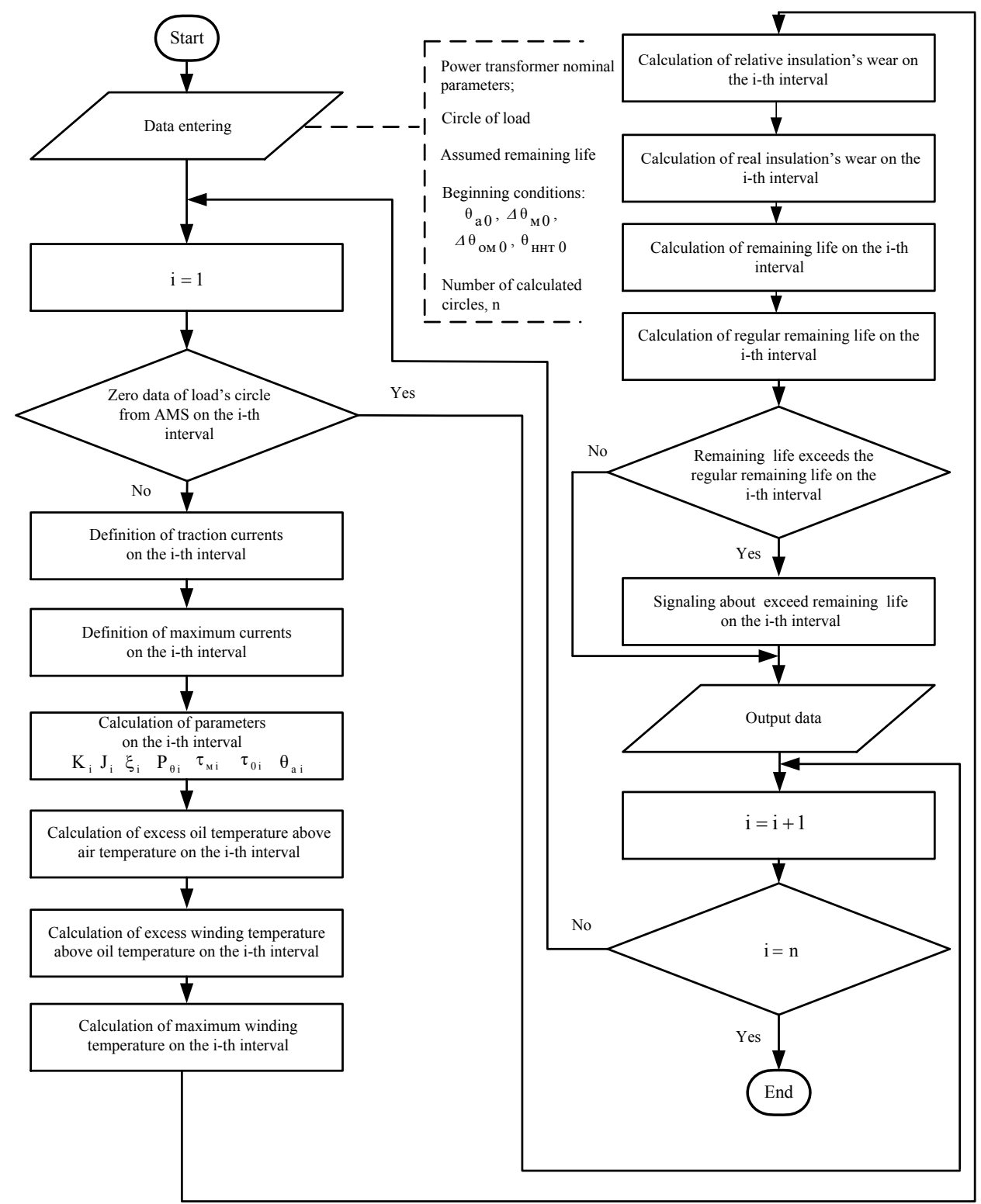

Fig. 2. Calculation algorithm

\subsection{Calculation module elaboration}

The calculation module elaboration was carried out with the help of the environment by graphic programming LabVIEW [17] for the compatibility with existing AMS. Calculation module is implemented on the basis of successive connections of function blocks and the addition of a text code using the Formula Node. The module consists of four subprograms, in each of which the parameters sequential calculation is carried out.

The module works as follows. AMS fixes the currents and phase angles values with a given time interval. Then these values come to the receiving blocks of the first subprogram. 
Here are the current values determined and the largest of them is selected. This subprogram's feature is a text code addition while it's writing. In the second and the third subprograms the calculated values are determined by the Top-Oil Temperature method, for example, the load factor, current density, etc. The algorithm assumes the use of real temperature values by direct measurement. The fourth subprogram, shown in Figure 3, includes blocks that produce computer operations to determine the actual wear of insulation, coefficient of wear, etc.

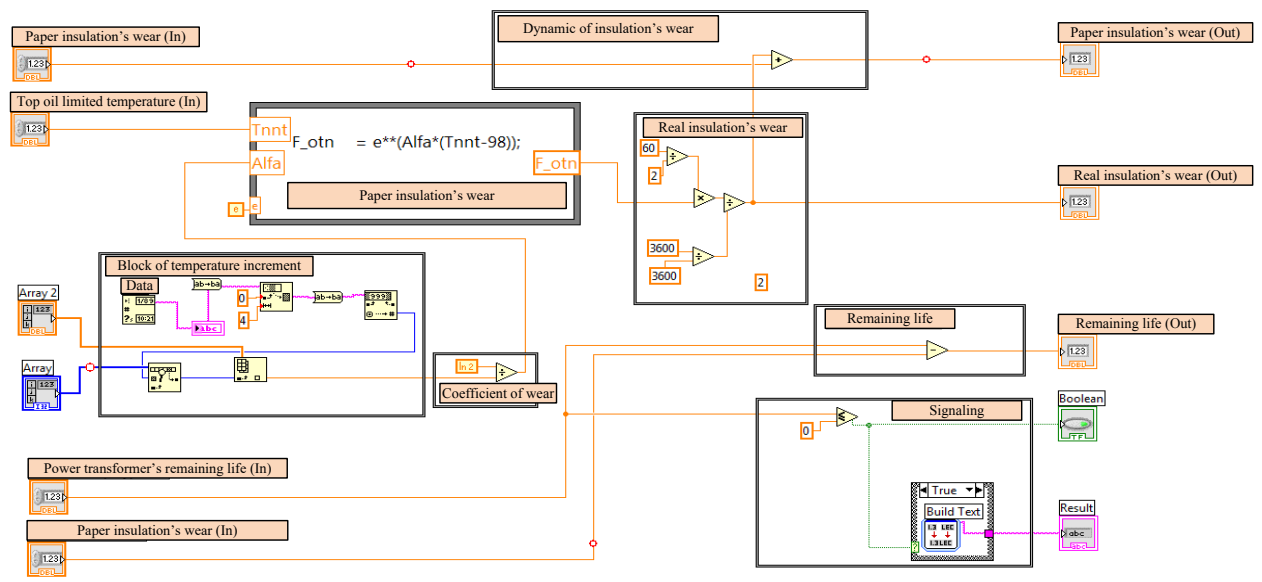

Fig. 3. The fourth subprogram's interface

Calculated values transmitted by the signal and perceived by the output blocks, which fix the final calculation results. Output parameters displayed graphically, which allows to visually assessing the dynamics of their changes in real time.

\section{Discussion}

The introduction into the existing AMS of a new additional module for calculating the transformer's remaining life allows visually monitoring the status of paper-oil insulation parameters in real time. Based on this information, decisions on the timing of power transformer's maintenance will be made. This system allows taking timely measures necessary to prevent emergencies.

\section{Conclusion}

Obtained results leads to the following conclusions:

1. The existing power transformers diagnostic systems do not take into account such basic features of the traction transformer's operation as the sharply variable nature of load changes and constant long-term overload of the traction transformer during heavy haul traffic.

2. The presence of a graphic interface and alarm signaling allows early taking measures to prevent emergencies and to avoid the power transformer's failure.

3. Modernization of the existing system by introduction into the existing AMS a new additional module for calculating the transformer's remaining life allows to expand its functionality without significant additional investments.

\section{References}

1. Joint Stock Company "Russian Railways" (JSCo "RZD")[CrossRef] 
2. National Academy of Indian Railways [CrossRef]

3. SAC Guodian Nanjing Automation Co., Ltd. [CrossRef]

4. Toshiba Infrastructure Systems \& Solutions Corporation [CrossRef]

5. Kapsch TrafficCom [CrossRef]

6. S. Makasheva Russ. Electr. Engin. 87: 107 (2016) [CrossRef]

7. P. Pinchukov, S. Polkhovskiy Pacific Rim Countries Transportation System 1 (1) (2013) [CrossRef]

8. E. Bastin, S. Makasheva Postulat 5 (2018) [CrossRef]

9. P. Pinchukov Russ. Electr. Engin. 87: 62 (2016) [CrossRef]

10. S. Makasheva Power quality monitoring in AC traction power system: monograph (2009) [CrossRef]

11. P. Pinchukov Jornal of Traction and Rolling Stock Institute of FESTU 12, 108-110 (2016) [CrossRef]

12. W.D.A.G. Hillary, K.L.I.M.P.B. Jayarathna, L.I. Ranasinghe, B. Samarakoon, N.M.T.N. Rathnayake, R. Lucas, R. Samarasinghe, Moratuwa Engin. Res. Con. (MERCon) (2017) DOI: 10.1109/MERCon.2017.7980513 [CrossRef]

13. General Electric - official site [CrossRef]

14. ABB - official site [CrossRef]

15. J. H. Harlow Electric Power Transformer Engineering, (CRC Press, Taylor\&Francis Group, 2017)

16. K. Zhou, Y. Huang, H. Li, T. Sun ICMIE 2016 MATEC Web of Conferences 7, 01005 (2016) DOI: 10.1051/matecconf/20167501005 [CrossRef]

17. LabView - official site [CrossRef] 